DOI: 10.14451/2.141.16

\title{
ПРОБЛЕМЫ ОРГАНИЗАЦИИ ДЕЛОПРОИЗВОДСТВА В АРБИТРАЖНЫХ СУДАХ
}

\author{
(ㄷ) 2020 Ланг Петр Петрович \\ начальник отдела анализа, статистики и обеспечения судопроизводства \\ Одиннадцатого арбитражного апелляционного суда, Россия, Самара \\ кандидат юридических наук, доцент кафедры гражданского и арбитражного процесса \\ Самарский государственный экономический университет, Россия, Самара \\ E-mail: petr.lang@mail.ru \\ (c) 2020 Чугурова Татьяна Викторовна \\ кандидат юридических наук, доцент кафедры гражданского и арбитражного процесса \\ Самарский государственный экономический университет, Россия, Самара \\ E-mail: ChugurovaTV@yandex.ru \\ (c) 2020 Котыхова Анастасия Александровна \\ магистрант факультета магистратуры \\ Самарский государственный экономический университет, Россия, Самара \\ E-mail: kotyhova2011@mail.ru
}

На современном этапе развития информационных технологий в системе ведения арбитражного судопроизводства актуально обращение к вопросам оптимального использования созданных технических возможностей. На сегодняшний день при ведении электронного документооборота существуют разнообразные проблемы: от отдельных вопросов при осуществлении делопроизводства до определения легитимности электронных документов. Электронный документ в судебной системе Российской Федерации является разновидностью письменного документа и должен занимать отдельное место в структуре доказательств.

Ключевые слова: делопроизводство, документооборот, суд, электронный документ, электронный документооборот, информационные технологии.

Инструкция по делопроизводству в арбитражных судах Российской Федерации (далее Инструкция) разработана на основе Федерального конституционного закона от 28.04.1995 № 1-ФК3 «Об арбитражных судах в Российской Федерации» [1], Арбитражного процессуального кодекса Российской Федерации [2] (далее - АПК РФ), иных нормативных правовых актов, регулирующих вопросы делопроизводства и судопроизводства, приказов Судебного департамента при Верховном Суде Российской Федерации, а также в соответствии с Государственной системой документационного обеспечения управления (ГСДОУ), Национальным стандартом Российской Федерации ГОСТ Р 7.0.97-2016 «Система стандартов по информации, библиотечному и издательскому делу. Организационнораспорядительная документация. Требования к оформлению документов» (ГОСТ Р 7.0.97-2016 [3]), указами Президента Российской Федерации, постановлениями Правительства Российской Федерации, приказами Судебного департамента при Верховном Суде Российской Федерации и нормативно-методическими документами Федеральной архивной службы России.

Инструкция устанавливает единую систему организации делопроизводства, порядок работы с процессуальными и иными документами, единые правила организации приема, регистрации, учета документов, их подготовки и оформления, рассмотрения, отправки и выдачи, печати и тиражирования, текущего хранения и передачи на хранение в архив, а также осуществления контроля за соблюдением установленных правил делопроизводства всеми структурными подразделениями арбитражных судов.

В настоящее время вопрос об электронном правосудии, о переходе всего судопроизводства в арбитражных судах исключительно на электронную платформу является одним из самых основных и приоритетных.

В реорганизации делопроизводства все еще остается проблема - технические средства, существующие на данный момент, все еще не на 
сто процентов востребованы и используемы и тем сам не разгружают судей от технической работы. Развитие электронного документооборота должно помочь в решении данной проблемы и развитии такого важного направления [4].

Электронный документ, равнозначный документу, подписанному собственноручной подписью, - это электронное сообщение, подписанное электронной цифровой подписью или иным аналогом собственноручной подписи (п. 11.1 ст. 3 ФЗ «Об информации, информационных технологиях и защите информации» [5]).

К определению понятия электронного документооборота можно выделить два подхода - в широком и узком смысле: в широком смысле электронный документооборот - это любой обмен в электронном виде компьютерными данными между различными субъектами; в узком электронный документооборот - это передача по телекоммуникационным каналам связи сообщений, автоматически сформированных и структурированных в соответствии со стандартами.

Электронный документооборот в суде - это деятельность суда и его аппарата, а также участников процесса по работе с движением документов, их обработке, направленная на оптимизацию таких процессуальных действий, как: обращение в суд (например, в рамках арбитражного судопроизводства заявление может быть подано в виде электронного документа, подписанного усиленной квалифицированной электронной подписью участника судопроизводства, его подающего); обмен процессуальными документами (лица, участвующие в деле, вправе представить исковое заявление, встречное исковое заявление, отзыв на иск, проект мирового соглашения, а также доказательства); получение судебных извещений (информация о принятии обращения, о времени и месте судебного заседания размещается судом на официальном сайте соответствующего суда в сети «Интернет»); изготовление судебных актов в форме электронного документа и их размещение в сети «Интернет» [6].

Среди производителей систем электронного документооборота принято следующее определение: «электронный документооборот - это механизм по работе с документами в электронном виде, то есть движение документов в организации с момента их создания (или получения) до завершения исполнения (или отправления), а также способ организации работы с документами, при котором основная масса документов организации используется в электронном виде и хранится централизованно».

Основные принципы электронного документооборота заключаются в следующем:

- однократная регистрация документа, которая способствует однозначной идентификации документа посредством любой инсталляции данной системы;

- возможность одновременного выполнения операций, что способствует сохранению времени передвижения документов и значительному повышению оперативности их выполнения;

- непрерывность передвижения документации, позволяющая производить идентификацию ответственного за исполнение задачи на каждом процессе жизнедеятельности документа;

- единая база документальной информации, позволяющая полностью исключить возможность дублирования документов;

- эффективность организованной системы поиска документа, при помощи которой можно находить необходимый документ, используя минимальную информацию о нем;

- развитие системы отчетности, что в свою очередь способствует полному контролю над движением документов в процессе документооборота и принятию управленческих решений, основанных на данных отчетных документов [7]

Необходимо отметить, что АПК РФ претерпело существенные изменения при введении норм об электронном документообороте. Такие изменения коснулись правил обращения в суд посредством заполнения специальной формы через официальный сайт суда и прикрепления к заявлению необходимых документов, судебных извещений, подготовки и рассмотрения дела, выполнения и направления судебных актов в электронном виде.

В настоящее время электронный документооборот в арбитражном процессе занимает значительное место: это и делопроизводство; и информирование о судебных заседаниях и принятых решениях, возможность в установленной форме обращениях в суд.

В настоящее время функционирует целый ряд электронных сервисов, позволяющих в полной мере раскрывать информацию о движении судебного дела, обо всех событиях, происходя- 
щих в процессе его рассмотрения, обо всех судебных актах, принятых по делу, равно как и о тех процедурах обжалования, которые проходят по данному делу. Электронная система позволяет обращаться к суду в электронном виде, подавать различные заявления, ходатайства, жалобы, а также обжаловать действия судей и сотрудников аппарата арбитражных судов.

На сегодняшний день все аспекты деятельности арбитражных судов охвачены электронными системами, позволяющими осуществлять арбитражное делопроизводство в электронном виде, и упрощающими процесс традиционного бумажного делопроизводства.

На сегодняшний день электронное делопроизводство пока остается альтернативой традиционному бумажному делопроизводству. Поэтому стороны сами решают, каким способом подать тот или иной документ в суд. Право на обращение в суд путем подачи документа в электронном виде закреплено в ч. 7 ст. 4 АПК. Для подачи документов достаточно заполнить специальную форму на сайте суда или отправить документ с помощью специализированных сервисов, таких как «Мой арбитр» или через личный кабинет пользователя на Интернет - портале ГАС «Правосудие», в необходимых случаях потребуется скрепление документов усиленной квалифицированной подписью. Предоставлять впоследствии бумажные оригиналы тех же документов не потребуется, что значительно сэкономит время сторон и их денежные затраты.

Использование специализированных сервисов для подачи документов позволяет отправить документ без задержек и уменьшить риск утери документов. Помимо предоставления процессуальных документов в суд, в электронном виде также можно предоставить и письменные доказательства. В статье 75 АПК предусматривается, что письменными доказательствами могут являться документы, подписанные электронной подписью в установленном законом порядке. Это говорит о том, что появилась возможность представлять доказательства не только на бумажном носителе, но и в электронном виде. Хотя на практике не все суды признают юридическую силу таких доказательств, так как очень сложно установить происхождение электронного документа, его принадлежность определенному лицу, неизменность доказательства.

Судебный акт с 1 января 2017 г. также может быть выполнен в форме электронного документа, подписанного усиленной квалифицированной электронной подписью. Согласно статье 169 АПК арбитражные суды по общему правилу должны выносить решение в форме электронного документа (за исключением случаев, когда суд по техническим причинам не может этого сделать), тогда как суды общей юрисдикции вправе выносить решения в электронной форме (статья 197 ГПК [8]). В случае изготовления судебного решения в электронной форме дополнительно к делу приобщается экземпляр на бумажном носителе. Значительно сократился и срок направления копий решения суда лицам, участвующим в деле. Если решение выполнено в форме электронного документа, то вместо пятидневного срока решение направляется не позднее следующего дня после дня его принятия посредством его размещения на официальном сайте суда в режиме ограниченного доступа [9].

Важно отметить, что в АПК РФ при введении норм об электронном документообороте появилось много новых изменений. Такие изменения коснулись правил обращения и подачи документов в суд посредством заполнения специальной формы через официальный сайт суда и прикрепления к заявлению необходимых документов, судебных извещений, подготовки и рассмотрения дела, выполнения и направления судебных актов в электронном виде. Электронный документооборот, безусловно направлен на упрощение процедур в арбитражном судопроизводстве, но все еще имеет свои недостатки [4, с.109].

На сегодняшний день существует проблема определения легитимности электронных документов, ввиду относительной легкости, с которой электронные документы могут подделываться или же они могут быть сфабрикованы. Суды на данный момент с подозрением относятся к электронным доказательствам и требуют предоставления доказательств в бумажном носителе. Так, например судья может потребовать представления подлинников доказательств в определенных случаях (невозможно разрешить дело без подлинников документов, представленные копии различны по своему содержанию; у судьи возникли сомнения в достоверности представленных доказательств) [6].

Электронный документооборот направлен на упрощение процедур в арбитражном судопроизводстве, однако, также имеет свои недостатки. Полагаем, что повышение транспарентности судопроизводства ставится в прямую 
зависимость от развития информационных технологий, где на судью и его аппарат ложится дополнительная нагрузка по размещению информации, а также риск ее распространения среди посторонних лиц в других целях.

Согласны с мнением Г.М.Рамазановой, о том, что на сегодняшний день существует проблема определения легитимности электронных документов, ввиду относительной легкости, с которой электронные документы могут подделываться или же они могут быть сфабрикованы. Суды на данный момент с подозрением относятся к электронным доказательствам и требуют предоставления доказательств в бумажном носителе [10].

Безусловно, права Т.Н.Самсонова, говоря о том, что электронный документ имеет свою специфику, которая обусловлена механизмом его создания, сохранения, внесения в него изменений и дополнений, и уничтожения. Полностью отождествлять документ традиционный и электронный нельзя [11].

Дискуссионные вопросы порождает спор о том, насколько электронный документ является самостоятельным доказательством или разновидностью традиционного документа. В соответствии с Постановлением Пленума Верховного Суда РФ от 26 декабря 2017 г. № 57 «О некоторых вопросах применения законодательства, регулирующего использование документов в электронном виде в деятельности судов общей юрисдикции и арбитражных судов» [12] электронный документ - документ, созданный в электронной форме без предварительного документирования на бумажном носителе, подписанный электронной подписью в порядке, установленном законодательством РФ.

Считаем, что электронный документ является разновидностью письменного документа и должен занимать отдельное место в структуре доказательств. Для этого необходимо дополнить АПК РФ положением об электронном документе. Статью 64 АПК РФ изложить в следующей редакции: «В качестве доказательств допускаются письменные и вещественные доказательства, объяснения лиц, участвующих в деле, заключения экспертов, консультации специалистов, показания свидетелей, аудио- и видеозаписи, электронные и иные документы и материалы».

Полагаем необходимым дополнить арбитражное процессуальное законодательство положениями об электронном документе. Под электронным документом необходимо понимать любую информацию, записанную на перфокарту, перфоленту, магнитный, оптический, магнитооптический накопитель, карту флеш-памяти и иной подобный носитель, которую можно аутентифицировать и (или) идентифицировать.

Другим аспектом рассматриваемой нами проблемы является усложнение общепринятых форм, а именно - сочетание бумажного и электронного документооборота. Согласимся с мнением Е.А. Семеновой, в соответствии с которым «Применение смешанного документооборота можно наблюдать повсеместно... Одной из серьезных проблем, требующих решения, является организация хранения информации в смешанном делопроизводстве» [13].

К сожалению, полный отказ от бумажного документооборота оказался невозможным на нынешнем этапе. Изменения в АПК РФ, связанные с обязанием сторон по делу обращаться к суду исключительно в электронном виде, несмотря на инициативы ВАС РФ, так и не были приняты. Такая позиция законодателей оправдывалась их сомнением в возможности преодоления так называемой «проблемы цифрового неравенства», существующей в Российской Федерации, то есть проблемы неравенства доступа к цифровым ресурсам в различных регионах страны и в различных социальных группах населения.

Высший арбитражный суд приложил немало усилий для разрешения проблемы территориального цифрового неравенства, в том числе предоставил доступ к своим сервисам через каналы мобильной связи, разработал системы мобильной картотеки арбитражных дел, обеспечил возможность гражданам и представителям организаций участвовать в судебных заседаниях с помощью видеоконференц-связи, а также обращаться к суду в электронном виде, опять же, с использованием мобильных устройств. Тем не менее, всех этих мер оказалось недостаточно для преодоления этой проблемы и, как следствие, вопрос об обязательности электронного документооборота и обязании сторон арбитражного процесса взаимодействовать с судом исключительно в электронном виде откладывается на неопределенный срок. Потому и остается необходимость сохранения двух видов документооборота - бумажного и электронного.

Инструкция по делопроизводству описала все возможные варианты взаимодействия судов 
между собой, судов со сторонами процесса, судов с органами государственной власти и управления как в бумажном, так и в электронном виде [14].

В будущем возможен полный отказ от бумажного делопроизводства в арбитражных судах.

Инструкция представляет собой кодифицированный документ, объединивший в себе целый ряд положений АПК РФ, значительную часть различных положений постановлений Пленума ВАС РФ, а также содержит целый ряд новелл. Документ построен по принципу общей и специальной норм, имеет общую часть, в которой описаны стандартные процедуры и правила, обязательные к выполнению на разных этапах прохождения судебных документов суда вне зависимости от инстанции, и особенную часть, в которой определена специфика документооборота в зависимости от судебной инстанции, рассматривающей дело.

Особенная часть Инструкции состоит из описания тех особенностей, с которыми сталкиваются арбитражные суды различных инстанций: особенности деятельности в части делопроизводства арбитражных судов первой, апелляционной, и кассационной инстанций, а также специализированного Суда по интеллектуальным правам.

Наличие большого количества процессуальных норм и правил, которые сосредоточены в Инструкции, и определило столь необычную форму ее утверждения и введения в действие. Ранее утверждение Инструкции оформлялось приказом председателя ВАС РФ, теперь же она утверждена Пленумом ВАС РФ с приданием соответственно этому документу статуса акта судебного толкования.

Делопроизводство в суде может быть организовано как централизованно, так и децентрализованно [11, с.49].

Инструкция имеет целый ряд особенностей и новелл. Эти новеллы в основном затрагивают те сферы деятельности, которые ранее были урегулированы исключительно информационными письмами, методическими рекомендациями и прочими документами и актами, издаваемыми ВАС РФ и его подразделениями различного уровня. В части организационных новелл можно указать закрепление в Инструкции фактически существующих ныне моделей организации делопроизводства в арбитражных судах РФ. Так, в ней зафиксирована возможность организации делопроизводства как по принципу централизованной, так и по принципу децентрализованной системы. При этом под централизованной системой понимается такая система, при которой судья получает процессуальные документы по делу от единого подразделения делопроизводства после их регистрации, совершает процессуальные действия с ними и затем передает документы для дальнейшей обработки в это же подразделение делопроизводства. Судья работает с документами только в периоды процессуальной активности по делу. Все вспомогательные функции осуществляются централизованным подразделением делопроизводства, находящимся в ведении руководителя аппарата арбитражного суда.

Децентрализованная система делопроизводства или система «Офис судьи» построена на ином принципе. В рамках данной системы каждый судья получает в свое распоряжение нескольких сотрудников аппарата, которые формируют его офис. Как правило, «Офис судьи» состоит из помощника судьи и секретаря судебного заседания. В ряде судов сюда также входит специалист, который помогает в обработке документов судье и осуществляет основные делопроизводственные функции. Система предполагает, что документы по делу после их регистрации передаются в «Офис судьи», где находятся вплоть до окончания рассмотрения дела и передачи его в архив. Все вспомогательные операции и функции осуществляются в пределах «Офиса судьи», и вся полнота ответственности по ведению делопроизводства по делу лежит на судье [11, с.51].

Инструкция допускает возможность существования смешанной модели организации делопроизводства. В этом случае часть функций выполняется централизованным подразделением, а часть функций ложится на «Офис судьи», который носит достаточно усеченный характер, то есть состоит из судьи и его помощника, а все вспомогательные функции, в том числе функции секретаря судьи судебного заседания сосредоточены в обособленных подразделениях арбитражного суда.

Как следует из Инструкции, выбор модели делопроизводства зависит не только от усмотрения суда и не столько от этого усмотрения, сколько от необходимости учитывать размеры суда, его территориальную удаленность и пространственную целостность. То есть нужно 
учитывать расположение подразделений суда в рамках одного здания или в рамках нескольких зданий, саму конфигурацию зданий, возможность создания единого пространства для размещения «Офиса судьи» или отсутствия такой возможности и т.п.

В настоящее время создание компьютерных систем протоколирования судебных заседаний, внедрение средств автоматизированного сбора и анализа первичной судебной информации является принципиально новым направлением информатизации судов. Унификация первичных информационных ресурсов является одним из важнейших условий эффективного информационного взаимодействия судов разных инстанций, следственных органов, органов прокуратуры и адвокатуры. Единая система электронного документооборота в судах предусматривает работу с унифицированными документами и единую систему классификации судебной информации, в том числе, с учетом нового вида - звуковой. В подобных условиях необходимо говорить о решении проблем организационного характера, поскольку дополнительная нагрузка в таком случае ложится на аппарат судьи. Эта проблема требует дополнительного исследования, так как действующие в судах инструкции по делопроизводству не отвечают подобным нововведениям $[14$, с.288].

Подводя итог, можно сказать о том, что современные технологии активно внедряются в нашу жизнь и заменяют привычные для нас способы работы. Введение электронного документооборота в судах позволяет сократить временные затраты как сторон, так и суда, что способствует реализации принципа процессуальной экономии. Но нужно помнить, что процессуальная экономия - не основная цель судопроизводства, а лишь способ его рационализации и оптимизации.

\section{Библиографический список}

1. . Федеральный конституционный закон от 28.04.1995 № 1-ФКЗ (ред. от 18.07.2019) «Об арбитражных судах в Российской Федерации» // Собрание законодательства РФ.-1995. - № 18. - Ст. 1589.

2. Арбитражный процессуальный кодекс Российской Федерации от 24.07.2002 № 95-Ф3 (ред. от 02.12.2019) // Собрание законодательства РФ.-2002.- № 30.- Ст. 3012.

3. ГОСТ Р 7.0.97-2016. Национальный стандарт Российской Федерации. Система стандартов по информации, библиотечному и издательскому делу. Организационно-распорядительная документация. Требования к оформлению документов (ред. от 14.05.2018) // Официальные документы в образовании.-2017.- № 18.

4. Машина, Н. С. Некоторые проблемы электронного документооборота в арбитражных судах / Н. С. Машина // Современные научные исследования: актуальные вопросы, достижения и инновации.-2019.- С. 108.

5. Федеральный закон от 27.07.2006 № 149-ФЗ (ред. от 03.04.2020) «Об информации, информационных технологиях и о защите информации» // Собрание законодательства РФ.-2006. - № 31 (1 ч.). - Ст. 3448.

6. Бойко, Н. Н. Использование электронного документооборота и электронного документа как доказательства в суде / Н. Н. Бойко Л. Р. Юлбердина // Право и государство: теория и практика. - 2019. - № 8 (176). - С. 108.

7. Бойко, Н. Н.Проблемы ведения электронного документооборота в суде / Н. Н. Бойко, Л. Р. Юлбердина // Вопросы российского и международного права.-2018.- Т. 8. № 10А.- С. 13.

8. Гражданский процессуальный кодекс Российской Федерации от 14.11.2002 № 138-ФЗ (ред. от 02.12.2019) // Собрание законодательства РФ.-2002.- № 46.- Ст. 4532.

9. Пахтусова, А. О. Электронный документооборот в российских судах / А. О. Пахтусова // Молодой ученый.2019. - № 46 (284). - С. 185.

10. Рамазанова, Г.М. О вопросах, связанных с определением подлинности электронных документов и их использования в качестве доказательств в гражданском и арбитражном процессе / Г. М. Рамазанова // Россия: пути решения и проблемы-2015: материалы Всероссийской научно-практической конференции студентов и аспирантов. Казань: Познание.-2015.-С. 121.

11. Самсонова, Т.Н. О проблемах перехода на безбумажный (электронный) документооборот / Т. Н. Самсонова // Алтайский вестник государственной и муниципальной службы. - 2015. - № 7.- С. 50.

12. Постановление Пленума Верховного Суда РФ от 26.12.2017 № 57 «О некоторых вопросах применения законодательства, регулирующего использование документов в электронном виде в деятельности судов общей юрисдикции и арбитражных судов» // Российская газета.-2017. - № 297.

13. Семенова, Е.А.Электронный документооборот в Арбитражном процессе / Е.А. Семенова // Советник юриста. - 2015. - № 5.- С. 69.

14. Делопроизводство и документооборот в юриспруденции: учебник / П.П. Ланг, Ю.В.Руднева, А. В. Фадеев, Т. В. Чугурова: под общей ред. П. П. Ланга.- Самара: ИП Зуев Сергей Анатольевич, 2020.- С. 127. 